\begin{tabular}{|c|l|}
\hline Title & $\begin{array}{l}\text { Dynamic Behavior and Spontaneous Differentiation of Mouse Embryoid Bodies on Hydrogel Substrates of Different } \\
\text { Surface Charge and Chemical Structures }\end{array}$ \\
\hline Author(s) & $\begin{array}{l}\text { Liu, Jian Fang; Chen, Y ong Mei; Y ang, Jing Jing; Kurokawa, Takay uki; Kakugo, A kira; Y amamoto, Kimiko; Gong, } \\
\text { Jian Ping }\end{array}$ \\
\hline Citation & $\begin{array}{l}\text { Tissue Engineering Part A, 17(17-18), 2343-2357 } \\
\text { https://doi.org/10.1089/ten.tea.2011.0034 }\end{array}$ \\
\hline Issue Date & 2011-08-25 \\
\hline Doc URL & http://hdl.handle.net/2115/47051 \\
\hline Rights & $\begin{array}{l}\text { Thisis a copy of an article published in the TISSUE ENGINEERING: Part A @ 2011 Mary A nn Liebert, Inc.; TISSUE } \\
\text { ENGINEERING: Part A is available online at: http:/Nww.liebertonline.com. }\end{array}$ \\
\hline Type & article \\
\hline File Information & Tissue Engineering A .pdf \\
\hline
\end{tabular}

Instructions for use 


\title{
Dynamic Behavior and Spontaneous Differentiation of Mouse Embryoid Bodies on Hydrogel Substrates of Different Surface Charge and Chemical Structures
}

\author{
Jian Fang Liu, Ph.D.(cand.), ${ }^{1}$ Yong Mei Chen, Dr. Sci.,, ${ }^{2,}$ Jing Jing Yang, Dr. Sci., ${ }^{2}$ \\ Takayuki Kurokawa, Dr. Sci.,,3 Akira Kakugo, Dr. Sci., \\ Kimiko Yamamoto, Dr. Med., ${ }^{4}$ and Jian Ping Gong, Dr. Sci. ${ }^{2}$
}

Differentiation of embryoid bodies (EBs) into particular cell lineages has been extensively studied. There is an increasing interest in the effect of soft hydrogel scaffolds on the behavior of EBs, such as the initial adhesion, dynamic morphology change, and differentiation. In this study, without adding any other bioactive factors in the serum-containing medium, dynamic behaviors of mouse EBs loaded on the surface of hydrogels with different surface charge and chemical structures are investigated. EBs adhered quickly to negatively charged poly(sodium p-styrene sulfonate) (PNaSS) hydrogels, which facilitates EBs spreading, migration, and differentiation into three germ layers with high efficiency of cardiomyocytes differentiation, similar to that on gelatin coated polystyrene (PS) culture plate. While on neutral poly(acrylamide) (PAAm) hydrogels, EBs maintained the initial spherical morphology with high expression of pluripotency-related markers in the short culture periods, and then showed the significantly greater levels of selected endoderm markers after long-time culture. EBs cultured on negatively charged poly(2-acrylamido-2-methyl-propane sulfonic acid sodium salt) (PNaAMPS) gels demonstrated the analogous behaviors with that of neutral PAAm gels at early differentiation phase (day $4+1$ ). Then, their adhesion, spreading and differentiation were quite similar to that on negatively charged PNaSS gels. The correlation between surface properties of hydrogels and EBs differentiation was discussed.

\section{Introduction}

E MBRYOID BODIES (EBs) provide three-dimensional (3D) environments that create cell to cell contacts and recapitulate part of the environment of the embryo. ${ }^{1}$ Therefore, in the in vitro study on a dimensional (2D) culture system, EBs are usually used for differentiation of embryonic stem (ES) cells. $^{1,2}$ Via formation of EBs, mouse ES cells can differentiate spontaneously into derivatives of three-embryoic germ layers: mesoderm, endoderm, and ectoderm. ${ }^{3,4}$ By manipulating the culture conditions in which EBs differentiate, cells within developing EBs will differentiate into more advanced stages of embryogenesis, resulting in various committed cell types including cardiomyocytes, adipocytes, chondrocytes, and so on. ${ }^{5-7}$ In addition to soluble molecules, growth factors, and morphogenetic factors known to induce differentiation of ES cells, a number of scaffold materials, including synthetic and naturally-derived biomaterials, have been utilized to direct differentiation of ES cells. ${ }^{1,8-12}$
As effective scaffolds, hydrogels are useful for promoting stem cell growth and differentiation toward the formation of tissues due to their structural similarity to macromolecularbased extracellular matrix (ECM) in biological tissue. ${ }^{13,14}$ Many types of hydrogels have been used as scaffold materials for embryonic stem (ES) cell differentiation, such as poly(ethylene glycol), poly(vinyl alcohol), poly(hydroxyl ethyl methacrylate), and poly(acrylamide) (PAAm) hydrogels. ${ }^{1,15}$ While these hydrogels are nontoxic and do not activate a chronic immune response, they also do not readily promote cellular adhesion and function, because most cells do not have receptors to hydrogel forming polymers. ${ }^{16}$ Further, because of the hydrophilic nature of hydrogels, ECM proteins such as fibronectin (FN), laminin (LM) and vitronectin typically do not absorb to the gel surface. ${ }^{17}$ Therefore, various cell-interacting components, such as ECM molecules, small peptide, and glycoproteins need to be incorporated to these culture systems. ${ }^{18,19}$ Combining with appropriate mechanical properties, chemical composition

${ }^{1}$ Department of Biological Sciences, Graduate School of Science, ${ }^{2}$ Faculty of Advanced Life Science, and ${ }^{3}$ Creative Research Institution Sosei, Hokkaido University, Sapporo, Japan.

${ }^{4}$ Department of Biomedical Engineering, Graduate School of Medicine, University of Tokyo, Tokyo, Japan.

*Current affiliation: Department of Chemistry, School of Science, Xi'an Jiaotong University, Xi'an, P.R. China. 
and biological signals, synthetic hydrogels have been modified and designed in a variety of ways to create suitable microenvironment for controlling ES cells differentiation toward preferential specific lineage. ${ }^{20-22}$

On biomaterial surfaces, cell behaviors are considered to be determined by the balance of the cell-cell adhesion and cell-substrate adhesion. ${ }^{23}$ Relatively weaker cell-cell adhesion and higher cell-substrate adhesion enhance the spreading of multicellular aggregates into a monolayered morphology on substrates. ${ }^{24}$ Conversely, weaker cellsubstrate adhesion favors the formation of spheroidal micro tissues from dispersed cells on the surface of biomaterials. $^{25,26}$ During cell-substrate interplay, the formation and evolution of focal adhesion (FAs) were ongoing, which not only provides physical links between ECM and intracellular cytoskeleton via membrane-bound receptors but also involves in a lot of signal transduction mechanisms through plaque proteins, such as vinculin, talin and paxillin. ${ }^{27}$ The cooperation between signaling pathways triggered by soluble factors, such as growth and differentiation factors, and ECM proteins have been shown to determine cell proliferation and differentiation. ${ }^{28,29}$

Our previous studies have shown that the amount of negative charges of hydrogels has a substantial influence on the behaviors of cells. ${ }^{30-33}$ It has been found that negatively charged hydrogels, such as poly(2-acrylamido-2-methylpropane sulfonic acid sodium salt) (PNaAMPS) and poly(sodium p-styrene sulfonate) (PNaSS), are suitable scaffolds for endothelial cell culture. When the gel was negatively charged with an absolute Zeta potential value higher than $20 \mathrm{mV}$, endothelial cells can adhere, spread, proliferate, and finally reach confluence on the gel surface, without any modification of cell adhesive protein. ${ }^{30-33}$ On the other hand, the dedifferentiated chondrocytes can spontaneously be re-differentiated to chondrocytes cells on neutral and low-charge-density hydrogels. ${ }^{34}$ Moreover, negatively charged gels can induce chondrogenic differentiation even in the insulin-free maintenance medium, while the neutral gels showed better performance for chondrogenic aggregation and differentiation when the inducible factors were added in the culture system. ${ }^{35}$ Based on these previous studies, we assume that the EBs behavior may be substantially affected by the surface properties of hydrogels. However, there is little study about the effect of negatively charged hydrogels on ES cells differentiation, not to mention on EBs behavior.

In this study, we investigate the behaviors of EBs on three kinds of synthetic hydrogel scaffolds with different chemical structures: two negatively charged hydrogels with sulfonic acid moieties, PNaAMPS, and PNaSS hydrogels, and one neutral hydrogels, PAAm. The PNaSS hydrogel is selected for its high hydrophobicity while PNaAMPS is very hydrophilic, although both contain the negative charge. EBs were loaded on these three hydrogels and on a gelatin-coated polystyrene (PS) and incubated in chemically defined ES culture medium without adding of Leukemia inhibitory factor (LIF), an inhibitor against differentiation, and any other bioactive factors. As a result, it was discovered that the EB behaviors strongly depend on the surface charge and chemical structures of hydrogels. On the negatively charged PNaSS gels, EBs immediately adhered, spread, and spontaneously differentiated into three germ layers, especially with high efficiency of cardiomyocytes differentiation. On the neutral PAAm gels, the spherical shape and size of EBs were well maintained with high expression of pluripotency at the short culture time ( $<3$ days) and then the EBs differentiated into endoderm cells for the long culture period. EBs on PNaAMPS gels showed behaviors similar to that on PAAm gels at a short period while their long-standing behaviors were more similar to that on PNaSS gels. These results have an implication in promoting tissue-engineered constructs through making use of hydrogel scaffolds with different surface charge and chemical structures.

\section{Materials and Methods}

\section{Materials}

2-Acrylamido-2-methyl-propane sulfonic acid sodium salt (NaAMPS) as a monomer, was obtained by neutralization of 2-Acrylamido-2-methyl-propane sulfonic acid (AMPS; kindly provided by Toagosei) with sodium hydroxide in ethanol, and purified by recrystallization from acetone. Sodium $p$-styrene sulfonate (NaSS; Tokyo Kasei Kogyo), as a monomer, was purified by recrystallization from ethanol, dried at $25^{\circ} \mathrm{C}$ in a vacuum. Acrylamide (AAm; Junsei Chemicals) was purified by recrystallization from chloroform. $N, N^{\prime}$ methylenebis-(acrylamide) (MBAA; Tokyo Kasei Kogyo), as a cross-linker, was purified by recrystallization from ethanol. 2-Oxoglutaric acid (Wako Pure Chemicals), sodium chloride (Wako Pure Chemicals), and sodium hydrogen carboxyl (Junsei Chemicals) were used as purchased.

\section{Hydrogel preparation}

Sheet-shaped homopolymer hydrogels, PNaAMPS, PNaSS, and PAAm gels were synthesized by radical polymerization. The chemical structures of PNaSS, PNaAMPS, and PAAm are shown in Figure 1. An aqueous solution of $1 \mathrm{M}$ monomer, the prescribed amount of MBAA (as a crosslinker) and $0.1 \mathrm{~mol} \%$ 2-oxoglutaric acid (as an initiator) were purged with argon to eliminate the inhibition effect of oxygen for polymerization. The amount of cross-linker, relative to the amount of monomer, varied for hydrogels. Specifically, $4 \mathrm{~mol} \%$ MBAA was used for synthesis of PNaAMPS and PAAm gels, and $10 \mathrm{~mol} \%$ MBAA for PNaSS gels. The precursor solution was poured into a reaction cell consisting of a pair of glass plates, separated by a silicone spacer of $1.0 \mathrm{~mm}$ thickness. The solution was irradiated with UV light (wavelength, $365 \mathrm{~nm}$ ) to facilitate polymerization at room temperature for $6 \mathrm{~h} .^{30}$

After gelation, the gels were separated from the glass plates and immersed in a large amount of normal saline for 1 week and the solution was changed two times twice daily to
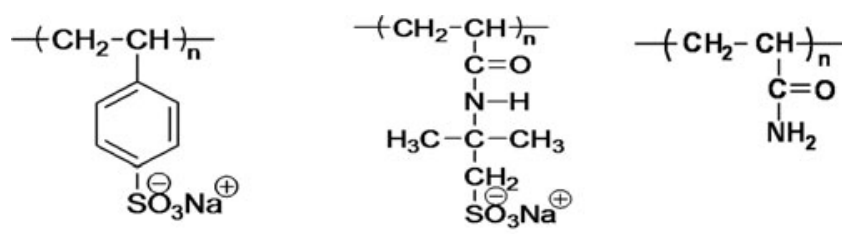

PNaSS

PNAAMPS

PAAm

FIG. 1. Chemical structures of polymers used in this study. 
remove un-reacted residual chemicals. The gels were then immersed in HEPES (Sigma-Aldrich) buffer solution (HEPES, $5 \times 10^{-3} \mathrm{M}$; $\mathrm{NaHCO}_{3}, 1.55 \times 10^{-2} \mathrm{M}, \mathrm{NaCl}, 0.14 \mathrm{M}$, $\mathrm{pH}$ 7.4). Phenol red $(0.4 \% \mathrm{v} / \mathrm{v})$ (Sigma-Aldrich) was used to visualize the $\mathrm{pH}$ of gels. After reaching equilibrium, the $\mathrm{pH}$ and ionic strength of the solution containing in the gels were adjusted to $\mathrm{pH} 7.4$ and $\sim 0.15 \mathrm{M}$, respectively. Gel disks were punched out by a hole-punch with a radius of $7.5 \mathrm{~mm}$. After being sterilized by autoclaving $\left(120^{\circ} \mathrm{C}, 20 \mathrm{~min}\right)$, the gel disks equilibrated in HEPES solution were placed in a 24-well PS tissue culture dish (Iwaki \& Co., Ltd.) for cell culture.

\section{Mechanical evaluation of hydrogels}

The elastic modulus of these hydrogels was evaluated by compression test with a tensile compressive tester (Tensilon RTC-1310A; Orientec, Co). The gel discs (15 mm diameter; $0.5-2.0 \mathrm{~mm}$ thickness) was set on the lower plate and compressed by the upper plate of the attachment, which was connected to a load cell, at a strain of $10 \%$ thickness $/ \mathrm{min}$. The elastic modulus was then determined by the average slope of the stress-strain curve over the strain range of $0-0.1 .^{36}$

The degree of swelling $q$ was measured as the weight ratio of the gel in its equilibrated state in HEPES buffer solution to that in its dried state. Each value was averaged over at least three parallel measurements. Table 1 is the elastic modulus $E$ and the degree of swelling $q$ of hydrogels in HEPES buffer solution. Each value was averaged over at least three parallel measurements.

\section{Detection of ECM proteins adsorbed onto the surfaces of hydrogels}

The amount of proteins that adsorbed on the surface of different hydrogels from the cell culture medium was characterized. The HEPES buffer-balanced gel disks with a diameter of $15 \mathrm{~mm}$, thickness of $\sim 2 \mathrm{~mm}$ were exposed to $1 \mathrm{~mL}$ mouse ES cell culture medium for $6 \mathrm{~h}$ at $37^{\circ} \mathrm{C}$ in a humidified atmosphere with $5 \% \mathrm{CO}_{2}$. Total protein adsorptions were detected using Nano Drop 1000A Spectrophotometer (Thermo Fisher Scientific) at A280. The adsorption of Dulbecco's modified Eagle's medium (without HEPES) was used as background, and that of mouse ES cell culture medium as prepared was regarded as an initial value. The amount of adsorbed protein was determined by the difference before and after contact with the hydrogels. Then the percentages of total protein adsorption on each hydrogels were calculated and compared.

The amount of ECM proteins, such as FN, collagen I (Col I), and LM adsorbed on the surface of different substrates

Table 1. The Elastic Modulus E and the Degree of Swelling $Q$ of PNaSS, PNaAMPs, and PAAm Hydrogels Swelling in HEPES Buffer at the Equilibrium State

\begin{tabular}{lcc}
\hline Hydrogels & Elastic modulus $(\mathrm{kPa})$ & Degree of swelling $(\mathrm{g} / \mathrm{g})$ \\
\hline PNaSS & $59.3 \pm 4.0$ & $17.8 \pm 0.9$ \\
PNaAMPS & $49.3 \pm 1.7$ & $21.6 \pm 0.9$ \\
PAAm & $33.5 \pm 1.1$ & $20.7 \pm 0.8$ \\
\hline
\end{tabular}

PAAm, poly(acrylamide); PNaAMPS; poly(2-acrylamido-2-methylpropane sulfonic acid sodium salt); PNaSS, poly(sodium p-styrene sulfonate). were quantitatively characterized via immune-fluorescence. After being exposed to the culture medium and washed with phosphate-buffered saline (PBS; Gibco), the gel disks and geltatin-coated PS were fixed with $4 \%$ paraformaldehyde for $20 \mathrm{~min}$ at room temperature, rinsed twice with PBS buffer and blocked with $0.5 \%(\mathrm{w} / \mathrm{w})$ bovine serum albumin (BSA). The primary antibodies, rabbit anti-FN (Chemicon), rabbit anti-Col I (Chemicon) and rabbit anti-LM (Sigma), diluted in PBS-BSA $(0.5 \%)$, were incubated for $2 \mathrm{~h}$ at $37^{\circ} \mathrm{C}$. Samples were then rinsed three times with PBS-BSA $0.5 \%$ and incubated with secondary fluoresceine-isothiocyanate (FITC)-conjugated goat anti-rabbit-IgG antibody (Chemicon). Finally, samples were rinsed with PBS and observed by fluorescence confocal laser scanning microscope (Eclipse TE2000-E; Nikon) equipped with a $20 \times$ objective. The fluorescence intensity differences between the gels incubated in a culture medium, corresponding to the amounts of absorbed FN, Col I, and LM on gel surfaces were measured. ${ }^{37}$

\section{Routine culture of mouse ES cells}

MGZ 5 ES cells, as derivatives of MG1.19 cells were maintained and cultured as previously described. ${ }^{38-40}$ The ES cells were maintained in Dulbecco's modified Eagle's medium (without HEPES; IBL Co., Ltd), supplemented with 20\% fetal bovine serum (Gibco), $1 \times$ nonessential amino acid, $1 \times$ nucleosides mix (Chemicon), $5 \times 10^{-5} \mathrm{M} \beta$-mercaptoethanol (Chemicon), and 1000 unit/mL LIF (Chemicon). The culture dishes (Iwaki \& Co., Ltd.) were prepared prior to cell seeding by coating with a solution of $0.1 \%$ porcine gelatin (SigmaAldrich) in PBS (Gibco-BRL). All cultures were performed at $37^{\circ} \mathrm{C}$ in a humidified atmosphere of $5 \% \mathrm{CO}_{2}$. After 2-3 days, ES cells were routinely passaged. The culture medium was changed every day. All mouse ES cells were used between passages 15-25.

\section{Culture of EBs on different substrates}

EBs were formed by hanging drop culture and suspension culture methods. ${ }^{41,42}$ First, hanging drop cultures were prepared to use $30 \mu \mathrm{L}$ droplets, each containing the number of ES cells desired to indicate the EB ( 1000). ES cells were allowed to aggregate in hanging drop for 2 days before transfer to liquid suspension cultures. Two days cultured EBs were removed from the droplets and cultured as suspension in $10 \mathrm{~cm}$ bacterial dishes (Iwaki \& Co., Ltd.) for 2 days. In this 4-day culture process, LIF was removed from the medium. After 4-day culture, the average cell number per EB was 62,700, with the diameter of about $600 \mu \mathrm{m}$. The viability characterization of EB was performed before seeding onto the gel surfaces. These EBs were used for the next experiment.

The gel disks were placed in a 24-well PS tissue culture dish and balanced in the mouse ES cell medium (without LIF) for at least $12 \mathrm{~h}$. After changing the culture medium, each EB was seeded onto the center of hydrogel surfaces and then cultured in the same medium with EB formation. EBs on neutral PAAm hydrogels were chosen as the comparison with EBs on negatively charged PNaAMPS and PNaSS hydrogels. Besides, EBs seeded onto a gelatin (0.1\%)-coated 24-well (PS) culture plate was considered as a control for comparison with EBs on hydrogels. At least 20 EBs were loaded on each of substrates. All of EBs were cultured until about 1 month in the same maintenance medium (without 
LIF) at $37^{\circ} \mathrm{C}$ in a humidified atmosphere with $5 \% \mathrm{CO}_{2}$. The following experiments on each substrate were repeated at least three times. To study the effects of hydrogels on EBs behavior, no other bioactive factors were added to the culture medium.

\section{Cell viability assay}

Before seeding onto the gel surfaces, the majority of cells within EB were viable while some dead cells sparsely distributed throughout the EBs, which indicated the relatively homogenous properties of initial EBs. After EBs were cultured on different substrates, the percentage of live cells within EBs at different times was quantitatively assessed by using the same method previously used to assay CNS stem and neural progenitor cell viability when cultured inside of collagen scaffolds. ${ }^{43}$

Cell viability of EBs was assessed before seeding on the substrates, using Calcein AM/EthD-1 Live/Dead Viability/ Cytotoxicity Kit (Molecular Probes). Calcein AM limitedly stains live cells via their intracellular esterase activity, producing an intense uniform green fluorescence (ex/em $\sim 495 \mathrm{~nm} / \sim 515 \mathrm{~nm})$. EthD-1 specifically stains dead cells with damaged membranes, producing a bright red fluorescence (ex/em $\sim 495 \mathrm{~nm} / \sim 635 \mathrm{~nm}$ ). Reagents were diluted according to the protocol and incubated $30 \mathrm{~min}$ in the serumfree medium. Images were recorded by a fluorescent microscope (Olympus).

\section{Dynamic image analysis}

Mouse ES cells and EBs were observed and recorded at varied culture time by a phase contrast microscope (Olympus) equipped with a digital camera (Olympus) using $20 \times$, $10 \times$, or $4 \times$ objective lens. In this study, the initially formed spherical EB that adhered on the gel surfaces was judged by shaking the tissue culture dish after loading on different substrates. After shaking, EBs that remained on the gel surface with unchanged location were considered as adhered on the gel surface. Otherwise, EBs were considered as suspension culture. EBs monitoring was first performed at $6 \mathrm{~h}$, and then monitored every day for 2 weeks. The scattered cell area $(A)$ and perimeter $(P)$ of EBs on different scaffolds were measured by image-pro plus 6.0 software.

The beating rates and area in spontaneous cardiomyocytes were measured through the video taken by the phasecontrast microscope (Olympus, IX71), using the image-pro plus 6.0 software. Each data point represents the mean \pm standard error of the mean (SEM). The methods have been previously introduced by other researchers. ${ }^{44,45}$

\section{Detections of alkaline phosphatase}

Alkaline phosphatase (AP) Detection Kit (Sigma-Aldrich, $86 \mathrm{R}-1 \mathrm{KT}$ ) was used as a specific and sensitive tool for the phenotypic assessment of ES cell differentiation by the determination of AP activity. ${ }^{46}$ The mouse ES cells cultivated in the medium with LIF, the initially formed EBs, and EBs cultured on the surface of hydrogels in the medium without LIF were fixed and stained following the procedures provided by the kit.

EBs cultured on different substrates were collected at different times, and digested with trypsin-EDTA. AP of EBs was quantitatively assessed by Quantitative Alkaline Phosphatase ES Characterization Kit (Milipore, SCR066). Under alkaline conditions $(\mathrm{pH}>10)$, AP can catalyze the hydrolysis of p-nitrophenylphosphate into phosphate and pnitrophenol, a yellow colored by-product of the catalytic reaction. The amount of $\mathrm{AP}$ can thus be reliably quantified by reading the amount of p-nitrophenol amassed after the catalytic reaction at $405 \mathrm{~nm}$ on a spectrophotometer. For each time point, approximately, 20,000 cells were assayed in triplicate as per protocol instructions.

\section{Reverse transcription-polymerase chain reaction and real-time polymerase chain reaction}

The gene expression level of a group of candidate pluripotency-related genes, named as Nanog homeobox (Nanog), Oct-4, SRY-box containing gene 2 (Sox2), developmental pluripotency associated 5A $(D p p a 5 a)^{47}$ were analyzed as the followed process. The cells of EBs were brushed off from each substrate and total RNAs were extracted using TRIzol (RiboPure kit, Ambion, AM1924) following the manufacturer's instruction. One microgram of total RNA per $20 \mu \mathrm{L}$ of reaction volume was reverse transcribed into cDNA using the PrimeScript RT reagent Kit (Takara, RR037A). Real-time polymerase chain reactions (PCRs) were performed and monitored using the SYBR Green PCR Mastermix and PCR apparatus (Takara, TP800). cDNA samples ( $2 \mu \mathrm{L}$ for total volume of $25 \mu \mathrm{L}$ per reaction) were analyzed for gene of interest and for the reference gene glyceraldehyde-3-phosphatedehydrogenase (GAPDH). The level of expression of each target gene was then calculated as previously described. ${ }^{37}$ The results were normalized to those of subcultured pluripotent mouse ES cells. Each sample was repeated at least three times for each gene of interest. Reverse transcription-PCR was performed at $95^{\circ} \mathrm{C}$ for $2 \mathrm{~min}$ followed by 34 cycles of $30 \mathrm{~s}$ denaturation at $95^{\circ} \mathrm{C}, 30 \mathrm{~s}$ annealing at the primer specific temperature, and $1 \mathrm{~min}$ elongation at $72^{\circ} \mathrm{C}$. The PCR primers were provided by Takara Corporation.

To clearly confirm the differentiation profiles on different scaffolds, the ectoderm-, mesoderm-, and endoderm-related expressions were evaluated. The expressions of ectoderm relative markers were analyzed, including nestin (Nes), Sex determing region Y-box 1(Sox1), orthodenticle homolog 1(Otx1), and neurogenic differentiation 1 (NeuroD). The selected endoderm expressions were analyzed, such as alphafetoprotein $(A F P)$, transthyretin (Ttr) and Albumin (Alb) genes. Moreover, the four mesoderm lineage markers were selected, including MyoD family inhibitor domain containing (mdfic), E-cadherin, Brachyury T (Bry T), and Dickkopf homolog 1 (Dkk-1), which will play important roles in mesoderm development. The cardiomyocyte-related markers were also analyzed, including early cardiac markers of Gata4, Nkx2.5, and late cardiac markers of $\alpha$-actin(c), and cardiac troponin $\mathrm{T}(c-T n T)$. The information about primers was shown in Table 2.

\section{Immunofluorescence staining}

For the staining of cytoskeleton and FAs as well as cardiomyocyte-related markers, EBs cultured on different substrates (day $4+10$ ) were transferred to gelatin coated cover-glass and grown for another 2 days, and then the specimens were rinsed with $1 \mathrm{~mL}$ chilled PBS for $10 \mathrm{~min}^{44}$ 
Table 2. Oligonucleotide Primers Used for Gene Expression Analysis by Real-Time Polymerase Chain Reaction

\begin{tabular}{|c|c|c|}
\hline Gene & Primer sequences $\left(5^{\prime}-3^{\prime}\right)$ & Location \\
\hline \multirow[t]{2}{*}{ GAPDH } & Fwd: TGTGTCCGTCGTGGATCTGA & $761-910$ \\
\hline & Rev: TTGCTGTTGAAGTCGCAGGAG & \\
\hline \multirow[t]{2}{*}{ DPPA5 } & Fwd: TCGGGCTAAATGGATGCTTCA & $340-477$ \\
\hline & Rev: ACAAGGACTGGAAACTGGCTTCAC & \\
\hline \multirow[t]{2}{*}{ Nanog } & Fwd: GAATTCTGGGAACGCCTCATC & $269-465$ \\
\hline & Rev: CCTTGTCAGCCTCAGGACTTG & \\
\hline \multirow[t]{2}{*}{ Oct4 } & Fwd: GGACATGAAAGCCCTGCAGAA & $451-596$ \\
\hline & Rev: GACAGATGGTGGTCTGGCTGAA & \\
\hline \multirow[t]{2}{*}{ Sox 2} & Fwd: AACCGATGCACCGCTACGA & 1001-1106 \\
\hline & Rev: TGCTGCGAGTAGGACATGCTG & \\
\hline \multirow[t]{2}{*}{ Nestin } & Fwd: GGGCCAGCACTCTTAGCTTTGATA & $5767-5871$ \\
\hline & Rev: TGAGCCTTCAGGGTGATCCAG & \\
\hline \multirow[t]{2}{*}{ Sox 1} & Fwd: AGAAATTATCTGCAGGGCCCAAG & 2876-2943 \\
\hline & Rev: AAAGTCACGGAAACGCTGCAC & \\
\hline \multirow[t]{2}{*}{ Otx1 } & Fwd: GTGGCACTCAAGATCAACCTG & $492-633$ \\
\hline & Rev: TCTCGCGTACTGGAGACGAC & \\
\hline \multirow[t]{2}{*}{ NeuroD } & Fwd: CGAGTCATGAGTGCCCAGCTTA & 1130-1197 \\
\hline & Rev: CCGGGAATAGTGAAACTGACGTG & \\
\hline \multirow[t]{2}{*}{$A F P$} & Fwd: AATGGTCCGGCTGTGGTGA & 1458-1557 \\
\hline & Rev: CAGCAGTGGCTGATACCAGAGTTC & \\
\hline \multirow[t]{2}{*}{ Ttr } & Fwd: AACTGGACACCAAATCGTACTGGAA & $301-437$ \\
\hline & Rev: GCTGTAGGAGTATGGGCTGAGCA & \\
\hline \multirow[t]{2}{*}{$A l b$} & Fwd: AGGCTACAGCGGAGCAACTGA & $1731-1858$ \\
\hline & Rev: TTTGCATCTAGTGACAAGGTTTGGA & \\
\hline \multirow[t]{2}{*}{ Mdfic } & Fwd: TCCACCAGGTATCAGGATTCCAA & 2339-2467 \\
\hline & Rev: TCCACATGAGCTGACTCCATCAC & \\
\hline \multirow[t]{2}{*}{ E-cadherin } & Fwd: TTCAACGCTACCAAGCAAACTGAC & 2795-2914 \\
\hline & Rev: GCAGGCATGATGGATGAGTTACA & \\
\hline \multirow[t]{2}{*}{ Bry $T$} & Fwd: CTAACGAGATGATTGTGACCAAGAA & $284-396$ \\
\hline & Rev: CGTCACGAAGTCCAGCAAGAA & \\
\hline \multirow[t]{2}{*}{$D k k-1$} & Fwd: GCCCAAGCAAGTGATTCCAGA & 1977-2053 \\
\hline & Rev: TTGGCTTAAGTTGGCAGGCTTC & \\
\hline \multirow[t]{2}{*}{ Gata4 } & Fwd: CGGAAGCCCAAGAACCTGAATA & $1562-1659$ \\
\hline & Rev: TTGCTGGAGTTACCGCTGGAG & \\
\hline \multirow[t]{2}{*}{$N k x 2-5$} & Fwd: AAGACCCTCGGGCGGATAA & $518-593$ \\
\hline & Rev: CCATCCGTCTCGGCTTTGT & \\
\hline \multirow[t]{2}{*}{$\alpha-\operatorname{actin}(c)$} & Fwd: GACCCAGATCATGTTTGAGACCTTC & $442-572$ \\
\hline & Rev: CATTATGAGTTACACCATCGCCAGA & \\
\hline \multirow[t]{2}{*}{$c-\operatorname{Tn} T$} & Fwd: CCATCGACCACCTGAATGAAGA & $776-925$ \\
\hline & Rev: CATTGATCCGGTTTCGCAGA & \\
\hline
\end{tabular}

Fwd, forward; Rev, reverse.

For fixation, the specimens were immersed in $200 \mathrm{~mL} 3.7 \%$ paraformaldehyde in PBS for $10 \mathrm{~min}$, followed by permeabilization with $200 \mathrm{~mL} 0.2 \%$ Triton X-100 in PBS for $10 \mathrm{~min}$, and then rinsed with $1 \mathrm{~mL}$ PBS buffer for $5 \mathrm{~min}$.. The specimens then were blocked with 5\% Goat serum in PBS solution $(1 \mathrm{~mL})$ for $30 \mathrm{~min}$. For actin fiber staining, the specimens were stained with $200 \mathrm{~mL}$ rhodamine-conjugated phalloidin (5 U/mL; Molecular Probes) for $1 \mathrm{~h}$ at $37^{\circ} \mathrm{C}$ in a humidified atmosphere of $5 \% \mathrm{CO}_{2}$. For the immunostaining of sarcomeric $\alpha$-actinin and FAs, the specimens were incubated with a primary antibody against sarcomeric $\alpha$-actinin (1:300; Abcam), vinculin (1:600; Sigma) overnight at $4^{\circ} \mathrm{C}$. Then FITCconjugated Goat-anti-rabbit IgG secondary antibody (1:500; Chemicon) were added for $1 \mathrm{~h}$ at $37^{\circ} \mathrm{C}$ in a humidified atmosphere of $5 \% \mathrm{CO}_{2}$, then washed three times with $1 \mathrm{~mL}$ PBS for $5 \mathrm{~min}$. To stain the cell nuclei, the cells were incubated in $2 \mu \mathrm{g} / \mathrm{mL}$ Hoechst 33258, followed by rinsing with
PBS. The images were recorded with a fluorescence microscope (Eclipse TE2000-E; Nikon).

\section{Statistical analysis}

Data are expressed as mean \pm the standard error of the mean (SEM) over $n \geq 3$ samples. Statistical significance was determined by analysis of variance (ANOVA single factor) with $p<0.05$.

\section{Results}

\section{Protein-surface interactions}

It has now been widely accepted that protein adsorption behavior was correlated with the bioactivity of a biomaterial surface ${ }^{48}$ Surface bioactivity is provided by the proteins that adsorb to the biomaterial surface following exposure of the 
surface to biological fluids, ${ }^{49}$ Because the surfaces of synthetic biomaterials are generally not bioactive themselves. It is well known that cell adhesion to most surfaces of tissue engineering scaffolds involves a two-step process. First, ECM proteins containing in serum medium adsorb onto surface of scaffolds, then cells adhere to these substrates mediated by the adsorbed proteins. ${ }^{50}$ The type and the amount of proteins adsorbed to the substrates determine the cell-substrate adhesion and the orientation of bioactive sites for cellular responses. ${ }^{51}$

To clarify the hydrogel effects on EB behavior, we first identified the surface properties of protein adsorption. The amount of protein contained in the ES culture medium that adsorbed to the surface of PNaSS, PNaAMPS, and PAAm gels, as well as on gelatin-coated PS was quantitatively characterized. As shown in Figure 2A, PAAm gels adsorbed the lowest amount of protein (8\%), which indicated that the proteins within serum are difficult to absorb to the neutral gel surface with a hydrophilic nature. While, the proteins were easier to adsorb to PNaSS gels that has a hydrophobic benzene ring $(42 \%)$ than that to other gel surfaces and gelatin-coated PS plate $(25 \%)(p<0.05)$. However, on another negatively charged PNaAMPS gel, the protein adsorption was only a little higher than that on neutral PAAm gels $(11 \%)$, and quite lower than that on PNaSS gels.

To confirm the adsorption of ECM proteins present in serum-containing culture medium to these surfaces, we further assessed the deposition of ECM proteins, such as FN, Col I, and LM. Immunofluorescent methods revealed the presence of FN, Col I, and LM on the surface of PNaSS, PNaAMPS, and PAAm gels as well as on gelatin-coated PS, after $6 \mathrm{~h}$ incubation in the presence of the serum-containing culture medium (Fig. 2B). Overall, the fluorescence intensity of adsorbed FN, Col I, and LM are in the similar tendency with that of total protein adsorption. Specifically, negatively charged PNaSS gels adsorbed the significant levels of FN, Col I, and LM proteins. In the case of another negatively charged PNaAMPS gel, low levels of adsorbed ECM proteins were found just like that on neutral PAAm gel.

Prior reports have shown that the hydrophilic hydrogel surfaces tend to interact with the charged and polar functional groups of the proteins, and thus influence adsorbed protein orientation. ${ }^{52}$ The higher adsorption on PNaSS gel suggested that hydrophobic benzene ring substantially enhances the protein adsorption. This result indicated that the adsorption of proteins is not only dependent on the charge but also on the hydrophobic moiety of the gels. In other words, these three gels can be classified into neutral gels with lower protein adsorption, negatively charged hydrophilic gels with low protein adsorption, and negatively charged hydrophobic gels with high protein adsorption as the ability of substrates to adsorb such proteins from serum containing culture medium determines their ability to support cell adhesion and spreading. ${ }^{53,54}$ Hence EBs behaviors may be differed from each other because of the variance of protein adsorptions onto these surfaces in this study.

\section{Time evolution of EB morphologies on different substrates}

To quantify EBs behaviors, we divided time dependent cell-substrate behaviors into three distinct developmental stages, an early differentiation phase (day $4+1$ ), an inter-
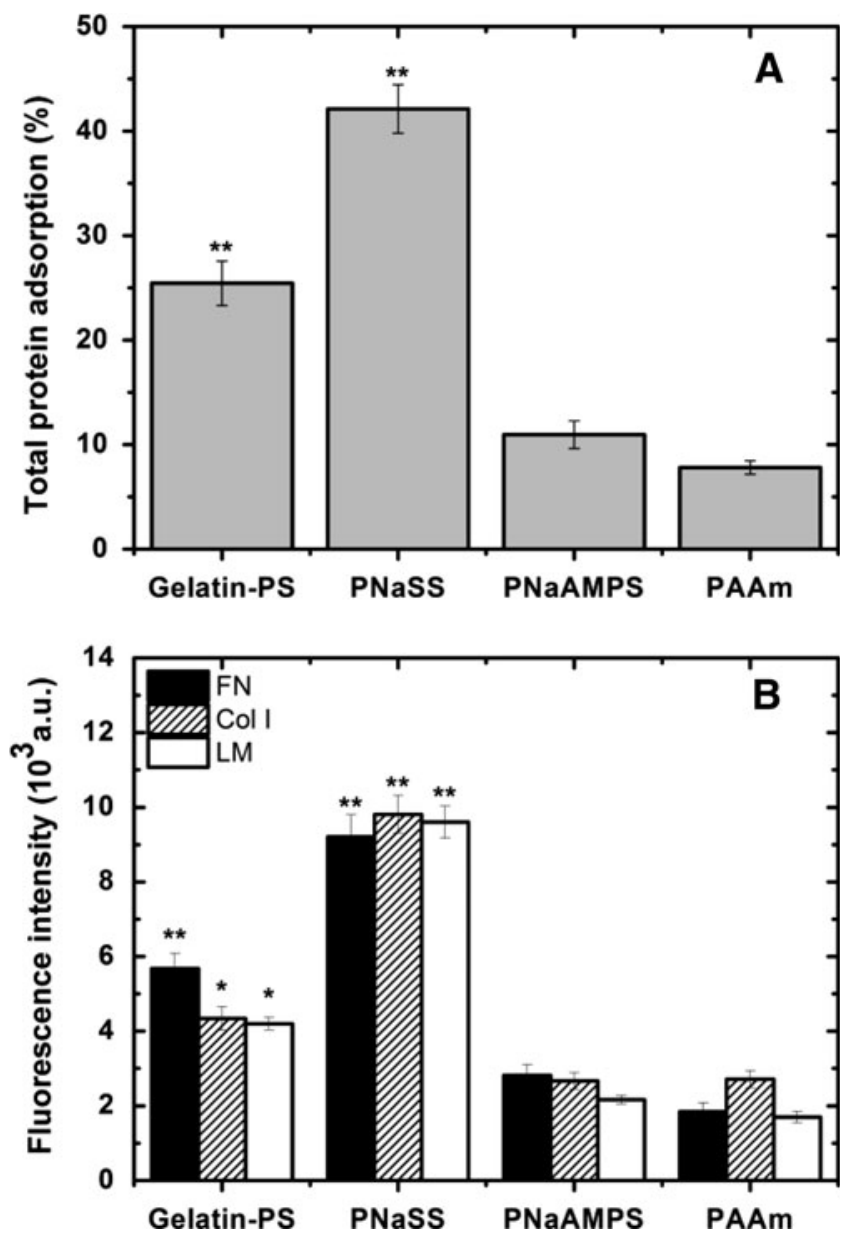

FIG. 2. The amount of proteins contained in the embryonic stem (ES) culture medium that adsorbed on the surface of poly(sodium p-styrene sulfonate) (PNaSS), poly(2-acrylamido2-methyl-propane sulfonic acid sodium salt) (PNaAMPS), and poly(acrylamide) (PAAm) gels, as well as on gelatin-coated polystyrene (PS) was quantitatively characterized. (A) The amounts of total adsorbed proteins on various substrates. (B) Fluorescence intensity of adsorbed fibronectin (FN), collagen I (Col I), and laminin (LM) on various substrates. Error ranges are standard deviations over $n=3-6$ samples. ${ }^{*} p<0.05$ and ${ }^{* *} p<0.01$ with respect to that on PAAm gels.

mediate phase (day $4+3$ ), and a terminal differentiation phase (day $4+10$ ). This classification is similar with the methods previously used for spontaneous beating cardiomyocytes studies. ${ }^{55}$

After loading the initially formed EBs (4 days aged, day 4) on different substrates, we investigated the effects of chemical structure and surface charge of gels on the EB adhesion, spreading, and migration. Figure 3 shows the phase-contrast microscopy images of EBs cultured on different substrates at an initial stage as well as a long-time period. At initial stage (6h), EBs on negatively charged PNaSS gel and gelatincoated PS were in adhesion to the surface, with the obvious scattered edge. Whereas, on another negatively charged PNaAMPS gel, the spherical EBs was not adhered to the surface until 1 day, similar to that on the neutral PAAm gel. The results showed that at initial stage, chemical structure of gels has an influence on EBs adhesion. 
Gelatin
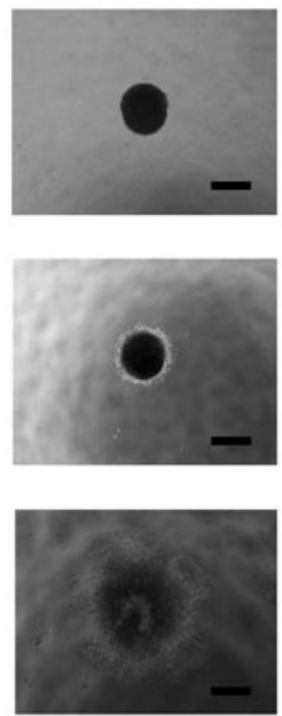

$3 d$

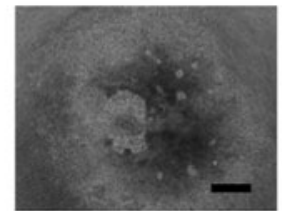

$7 d$

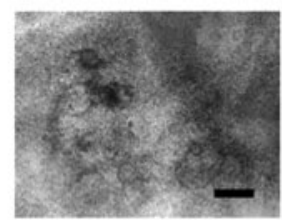

10d

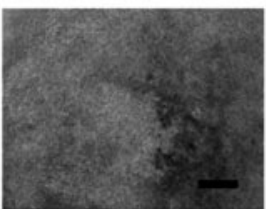

$15 d$

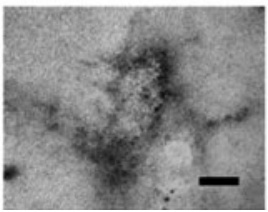

PNaSS
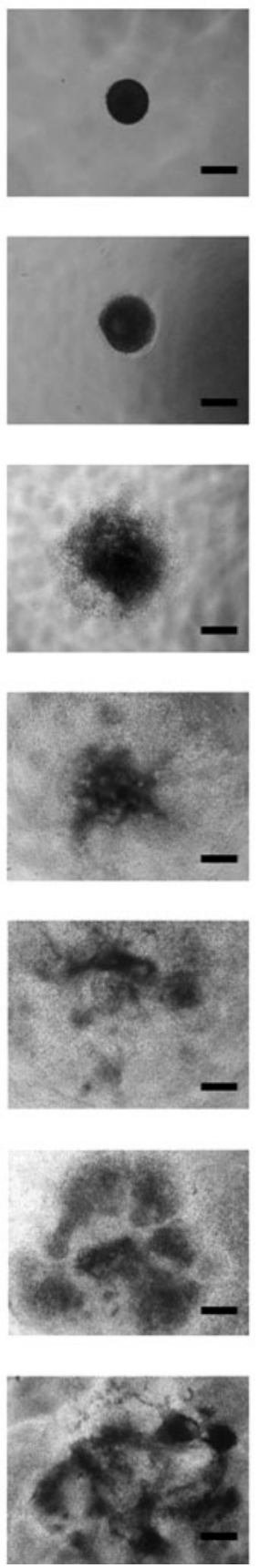

PNaAMPS
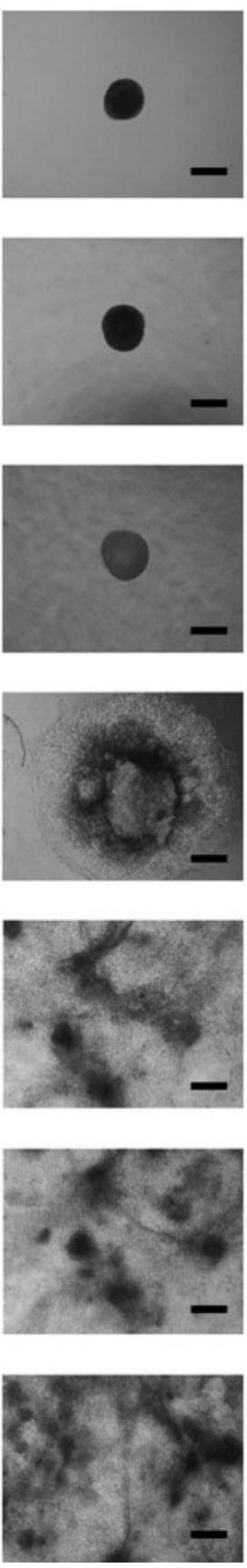

PAAm
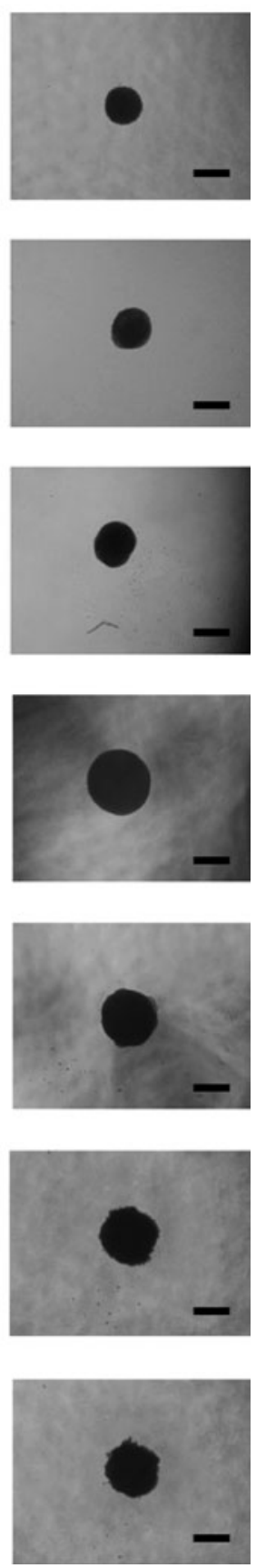

FIG. 3. Time evolution of embryoid bodies (EBs) morphologies on PNaSS, PNaAMPS, and PAAm gels as well as on the gelatin-coated PS culture plate. Culture time was relocated when EBs were seeded on the gel surfaces. Scale bar: $600 \mu \mathrm{m}$.
After 3-days cultures, adhered EBs scattered more extensively and migrated in the collective way onto the gelatincoated PS plate, and PNaSS gels. The front edges of EBs expanded on the surface mainly in monolayer. In the subsequent culture time, the collective migrations continued and the three dimensional structures of EBs partly disappeared on these two substrates. On another negatively charged PNaAMPS hydrogel, EBs adhere obviously at 3 days and exhibited similar scattered morphology to that on gelatincoated PS plate and PNaSS gels. Overall, on gelatin-coated PS, PNaSS, and PNaAMPS gels, EBs area $(A)$ were shown as alike increasing tendency (Fig. 4), which was clearly different from that on neutral PAAm gel. On the latter, EBs did not adhere tightly to the surface of scaffold even after 3 days, grown in the suspension-like state, maintaining spherical shape during the whole culture period. Moreover, the size of EBs did not increase obviously, with slight change in area and perimeter with time evolution. These results indicated that cells within EB spread little on nonionic PAAm gel. However, cells within EB spread and migrated evidently on strong polyelectrolyte gels with negatively charged sulfonate functional groups.

We then schematically summarize EBs dynamic behaviors on different substrates in Figure 5. Due to higher ECM protein adsorption comparing to unmodified PS and most hydrogel surfaces, gelatin-coated PS could facilitate and increase ES cell 

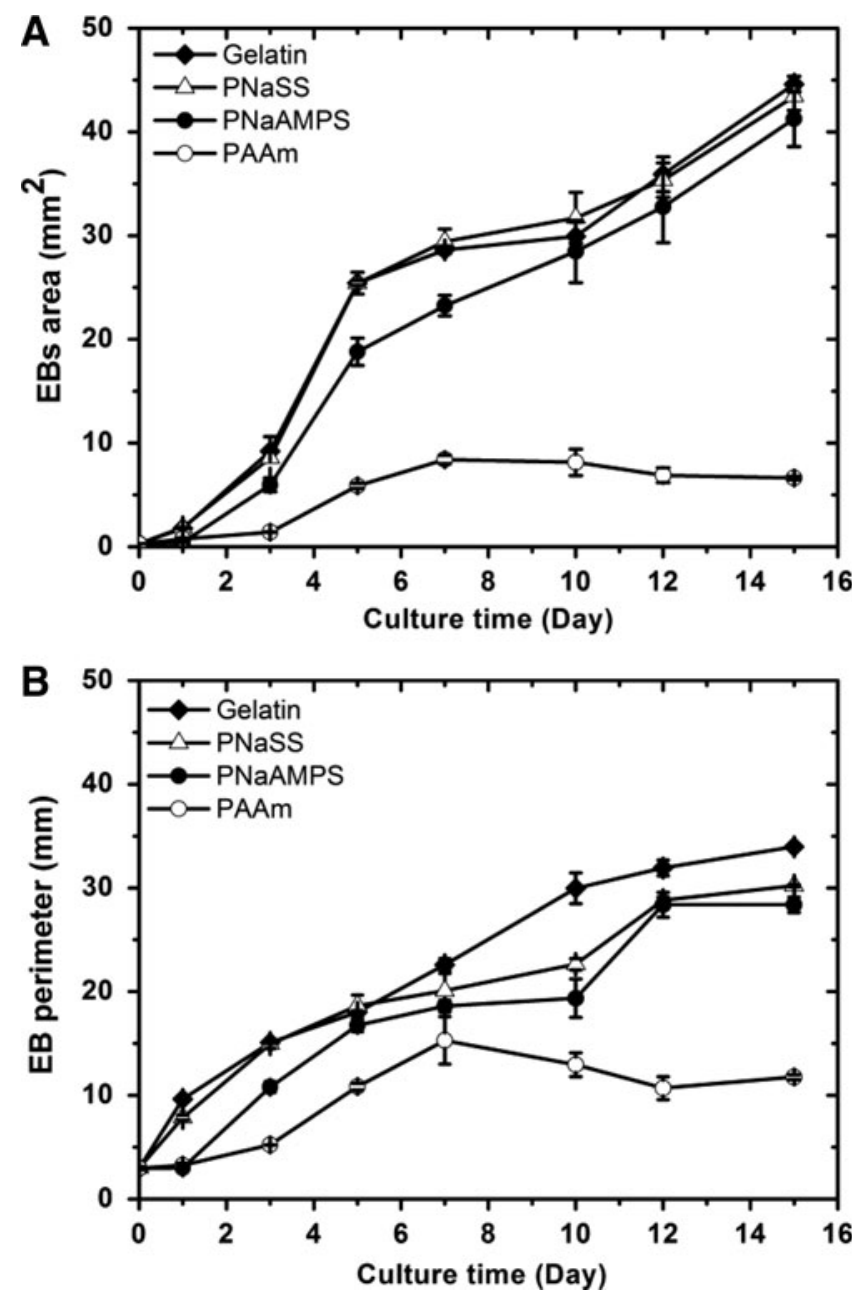

FIG. 4. EB area $A(\mathbf{A})$ and EB perimeter $P(\mathbf{B})$ on PNaSS, PNaAMPS, and PAAm gels as well as on the gelatin-coated PS culture plate. Culture time was relocated when EBs were seeded on the gel surfaces. Error ranges are standard deviations over $n=3-6$ samples.

adhesion. Cells within EBs migrated outward and originated outgrowths. After 14-days cultures, EBs on this surface underwent a ten-fold increase of their original size (Fig. 4), in sharp contrast with that on neutral PAAm gels.

EBs behavior on PNaSS hydrogels can be illustrated by protein-surface interaction too. Due to better performance of ECM protein adsorption than other substrates, cells with EBs quickly adhered onto the surface, and the cell-PNaSS gel adhesion was stronger than cell-cell interaction. As a result, the 3D spherical structures were inclined to form the monolayer on the substrate and migrate in the collective way. EBs development was followed by adhesion, spreading and migration on this surface.

EBs on negatively charged PNaAMPS gels showed a combined behavior of that on neutral PAAm gel and on PNaSS gels. At early differentiation phase (day 4+1), EB did not adhere to the substrates due to weak ECM protein adsorption. However, at a longer culture time ( $>3$ days), EBs showed similar behavior to that on PNaSS gel probably because of the electrostatic interaction between cells from EBs and substrate.
Determination of pluripotency of EBs on different substrates

The pluripotency of the mouse ES cells were associated with the expression of expression of AP, Oct 4 transcription factor (Oct4), and Nanog homeobox (Nanog). ${ }^{47}$ To determine whether the differences observed by the optical microscope were reflected in the pattern of gene or protein expression, we analyzed AP expressions as well as the gene profiles of a group of candidate pluripotency-related genes, including DPPA5, OCT4 (POU5F1), NANOG, and SOX2.

As shown in Figure 6A, the AP-positive cell clusters were well found on the subcultured pluripotent mouse ES cells and initial EBs. After 3-days cultures on various substrates, AP-positive cells within EB exhibited a significant diversity. Specifically, AP was greatly expressed in the aggregated cells cultured on neutral PAAm gels. On the other hand, AP was rarely found on PNaAMPS gels, PNaSS gels, and on gelatincoated PS plate.

To clarify the dynamic changes of AP expressed in EBs cultured on different substrates, we quantitatively analyzed the amounts of AP by comparing the optical density at $405 \mathrm{~nm}$ as shown in Figure 6B. AP expressions demonstrated in a decreased tendency along with the culture time on all substrates. At early differentiation phase (day $4+1$ ), the expression of AP on PNaAMPS gels and PAAm gels were higher than that on gelatin-coated PS, PNaSS gels and initial formed EBs. However, at an intermediate phase (day $4+3$ ), distinct high expression of AP was only possessed on EBs on neutral PAAm gels. Then at terminal differentiation phase (day $4+10$ ), the amounts of AP were decreased and reached the equivalent level among all substrates. Besides, the spherical structures of EBs on PNaAMPS gels were well correlated with its high expression of AP after day 1 . The results indicated that at initial stage, cells within EBs on PNaAMPS gels sustained the relatively higher undifferentiated state than that on another negatively charged PNaSS gels.

Then we evaluated the cell viabilities of EBs as the function of the effects of substrates through the use of Live/Dead staining. As shown in Figure 6C, the undifferentiated mouse ES cells and initially formed EBs showed high levels of viability $(98.2 \pm 0.8 \%$, and $95.2 \pm 0.2 \%$ respectively). With the increase in the culture time, the percentages of viable cells within EBs on all of substrates were decreased. After 2 weeks of culture, the cell viabilities within EBs were decreased to $58.04 \% \pm 4.6 \%$ on gelatin-coated PS plate, $62.17 \% \pm 3.7 \%$ on PNaSS gels, $71.28 \% \pm 3.8 \%$ on PNaAMPS gels, and $68.32 \% \pm 5.2 \%$ on PAAm gels. All of these values were higher than that of EBs in suspension culture after day $4+10$ $(54.28 \% \pm 4.2 \%)$. Moreover, at all of three time points, cell viabilities of EBs on PNaAMPS gels were higher than that of EBs on other substrates, which was consistent with AP characterization results.

Real-time PCR results supported the effects of substrates on the pluripotency of mouse ES cells. As shown in Figure $7 \mathrm{~A}$, at early differentiation phase (day $4+1$ ), the gene expressions of DPPA5, OCT4 (POU5F1), NANOG, and SOX2 were largely reduced on gelatin-coated PS plate. At the same time, these expressions in EBs on PNaAMPS gels and PAAm gels were well observed in the higher level better than that of initial formed EBs and EBs in suspension (day 5). 


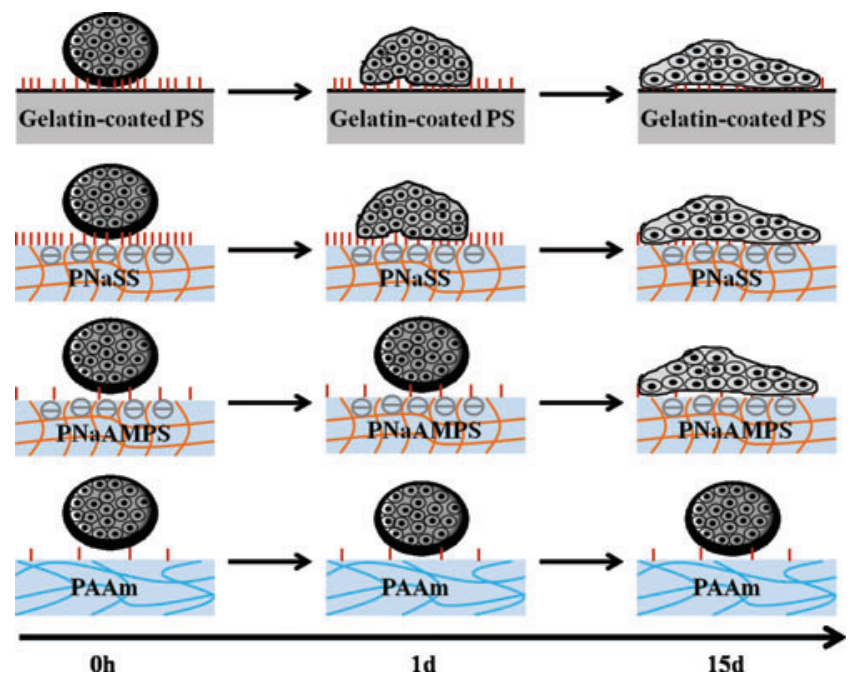

FIG. 5. Side view illustration of EBs dynamic behaviors on various substrates. Protein adsorbed onto substrates was shown in red vertical line, and the amount of these lines means the difference of adsorbed proteins on various substrates before EBs loading. Color images available online at www.liebertonline.com/tea

Figure 7B shows the varied expressions of these 4 genes in cells within EBs at an intermediate phase (day 4+3). The similar low levels of pluripotent gene expressions were found on negatively charged substrates (PNaSS, PNaAMPS, and gelatin-coated PS), demonstrating about 0.1 -fold relative to the subpassage undifferentiated mouse ES cells. On neutral PAAm hydrogels, the expressions of DPPA5, NANOG, and SOX2 genes were even higher than that of initially formed EB and EBs (day 7) in suspension culture. At terminal differentiation phase (day $4+10$ ), all of 4 genes expressions in EBs grown on PAAm gels were decreased and significantly lower than that of cells at earlier culture periods and EBs (day 14) in suspension culture (Fig. 7C). These results suggested that cells within EBs on PAAm gels had clearly differentiated after long-time period of culture, although they kept the original spherical shape (Fig. 3).

\section{Differentiation profiles of EBs on different substrates}

In the case of the mouse embryonic development, endoderm, together with mesoderm and ectoderm, is formed from the ectoderm of the epiblast through the process of gastrulation beginning at approximately 6.5 of gestation. ${ }^{41}$ When EBs was seeded on various surfaces, the differentiation of cells within EBs was continued and affected by the substrate. We further evaluated the differentiated ectoderm, mesoderm, and endoderm-related expressions by semiquantitative analysis of specific genes expressions at terminal differentiation phase (day $4+10)$. Owing to the relatively homogeneous source of EBs, the initial three germ-layered expressions of EBs were considered no difference and used as normalization in the next part.

We firstly investigated the expressions of ectoderm markers, which is located in the outmost layer of three germlayered animal embryos and will develop into the skin and nervous tissue. As shown in Figure 8A, nestin, a common marker for the early ectoderm, was in slightly higher upregulation in negatively charged gels than that on neutral
PAAm gels and gelatin-coated PS plate. There is no statistical difference versus the initial formed EBs. In short, the distinct upregulations of Nestin, Sox1, Otx1, and NeuroD were not found on all of substrates.

Figure $8 \mathrm{~B}$ shows the selected endoderm expressions involving $A F P$, Ttr, and Alb genes in EBs on different surfaces after 10 days culture. Ttr expression is an indicator of the development of visceral endoderm, and $A l b$ gene expression is enriched by endoderm cells development. ${ }^{41}$ Expression of $A F P$, a commonly used endoderm marker, was upregulated in EBs on all different surfaces. Especially, the distinctly higher expressions of AFP and Ttr on PAAm gels were found than that on negatively charged gels with 100 -folds relative to initially formed EBs.

Figure 8C shows the expressions of mdfic, E-cadherin, Bry $T$ and $D k k-1$, which will play important roles in mesoderm development. ${ }^{56}$ Almost all of these four genes expressions increased when EBs were cultured on different substrates than on initially formed EBs. Greater levels of Bry $T$ were found on negatively charged PNaAMPS and PNaSS gels, which indicated that these two gels favor differentiation of posterior mesoderm to some extent. Besides, the relatively high expressions of mdfic genes on PNaSS gels were found.

In brief, as for EBs cultured on hydrogels with different chemical structure and charge, upregulation of endoderm and mesoderm-related expressions were well observed. The close developmental association between mesoderm and endoderm, possibly through a common progenitor, suggests that the same mechanisms regulating the early induction events lead to the establishment of these linegage. These results were the same with previous report. ${ }^{56}$

\section{Differentiation of EBs into cardiomyocytes}

At different culture days postplating on various substrates, we observed the spontaneous cardiomyocyte differentiation by recognizing the periodical beating of EBs outgrowth. Figures $9 \mathrm{~A}$ and B show the time profile of beating rates and beating area of EBs on various substrates, respectively. All the culture time was denoted as the seeding time of EBs on different surfaces. In general, contracting cells within EBs were identified at 1-7 days after seeding on different surfaces. At a later time, the profiles of contraction rate and beating areas of EBs outgrowth were differed from each substrates and at day 30, almost no beating cells was observed.

The heterogeneity in cardiomyocytes differentiation on different substrates was observed along with the time evolution. As shown in Figures 9A and B, the beating rates and areas change dynamically over a period of about 1 month. On gelatin-coated PS culture plate, beating cells were first observed at day 1 with the beating area of $\sim 10 \%$. The beating area increased with time (day 1 to 10 ), and reached $\sim 30 \%$ of total EBs outgrowth at day 10 . After day 10, the beating rate and area did not increase further (day 10-18) and disappeared after day 21.

On other substrates, beating cells were firstly observed at different time points; day 4 (on PNaAMPS gels), and day 7 (on PNaSS and PAAm gels). Both PNaAMPS and PNaSS gel enhanced the beating rates and areas from day 7 to 14 , followed by a decrease. At day $14, \sim 40 \%$ of the total EB outgrowth was beating on these two negatively charged gel 
A

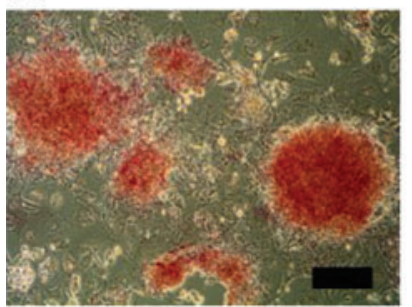

mESCs

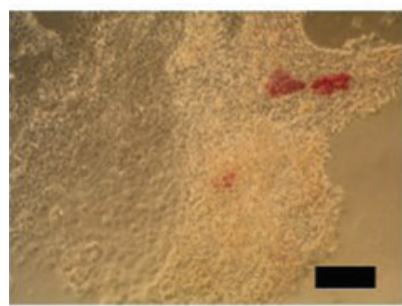

Gelatin-coated PS (3d)

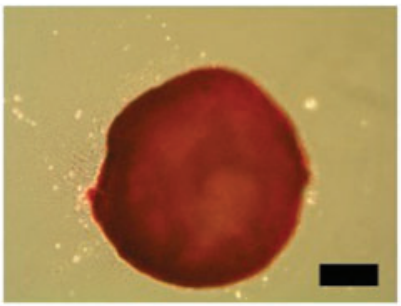

EB

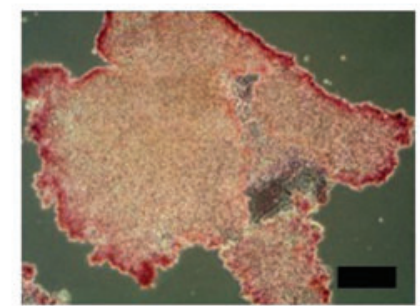

PNaSS (3d)

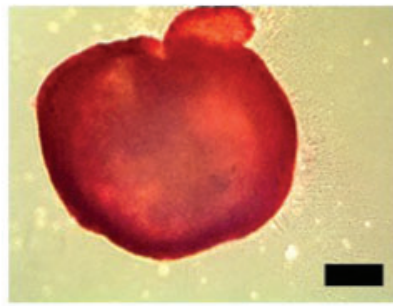

PAAm (3d)

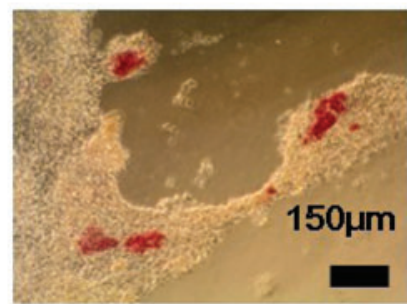

PNaAMPS (3d) cells, initially formed EBs (day 4), EBs after 3 days culture on PAAm, PNaSS, and

PNaAMPS gels as well as on the gelatin-coated PS culture plate. Scale bar: $150 \mu \mathrm{m}$. (B) Quantitative AP analysis of EBs after 1-day, 3-days, and 10-days cultures on different substrates. (C) Cell viability of EBs after 1 day, 3 days, and 10 days culture on different substrates. ${ }^{*} p<0.5$ versus the AP expressions of EBs in suspension culture. ${ }^{* *} p<0.01$ versus the AP expressions of EBs in suspension culture. Color images available online at www.liebertonline.com/tea

B
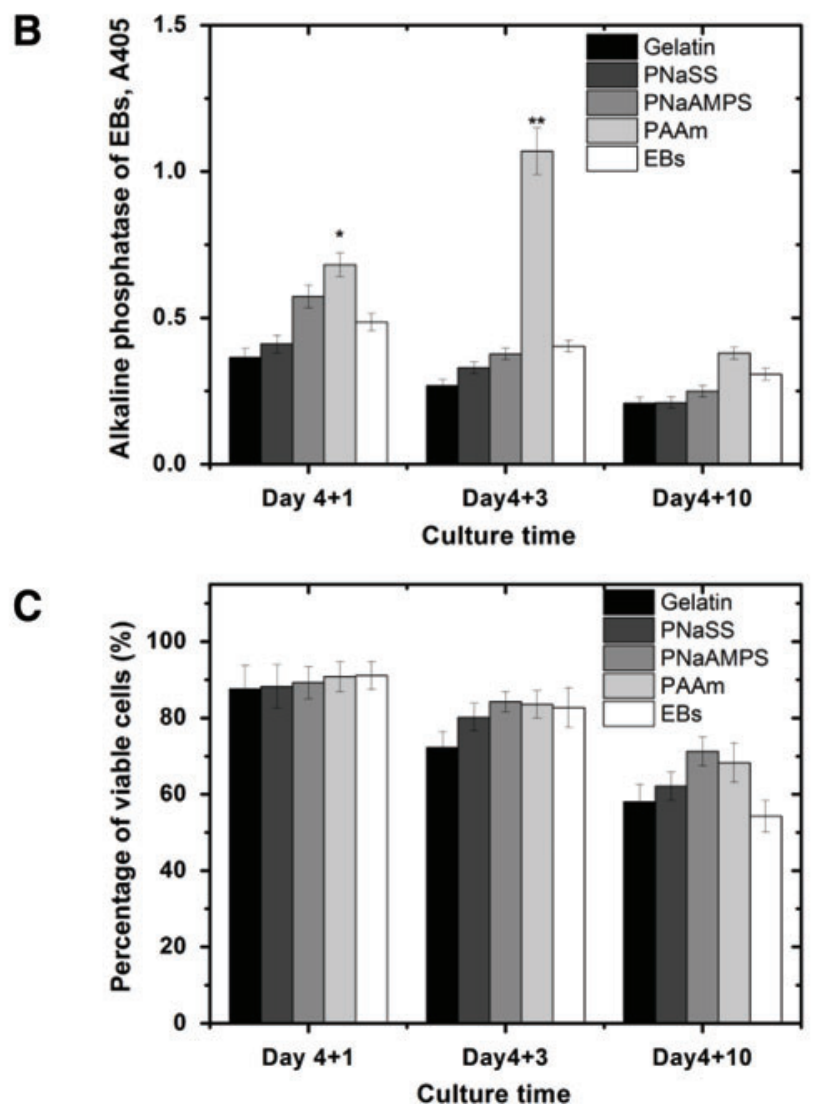

surfaces. The disappearance time of beating cells on PNaSS and PNaAMPS gels was 21 and 24 days, respectively. On PNaAMPS gels, the first contracting cells appeared earlier than on PNaSS gels with higher beating rates. In the case of PAAm gels, the beating rates were kept constant during the culture periods of days 7-18, while the beating areas increased at first 14 culture days followed by a decrease and disappearance (at day 21).

Real-time PCR analysis of EBs on different substrates (day $4+10$ ) have demonstrated that cells within beating EBs showed the expressions of cardiac transcription factors, in- cluding Gata-4 and Nkx2.5, and of cardiac-restricted genes, including $\alpha$-actin(c), and $c-T n T^{57}$ as shown in Figure 9C. EBs cultured on negatively charged PNaAMPS gels showed distinct increases of Gata-4, Nkx2.5, $\alpha$-actin(c), and $c-T n T$ expressions with higher levels than that on other substrates. Moreover, upregulation of $c-T n T$ expression was only not found on PAAm gels. However, these expressions on neutral PAAm gels did not increase obviously comparing to initially formed EBs.

Combining with Figures $9 \mathrm{~A}$ and $\mathrm{B}$, the expressions of cardiomyocyte differentiations were in the order from higher 

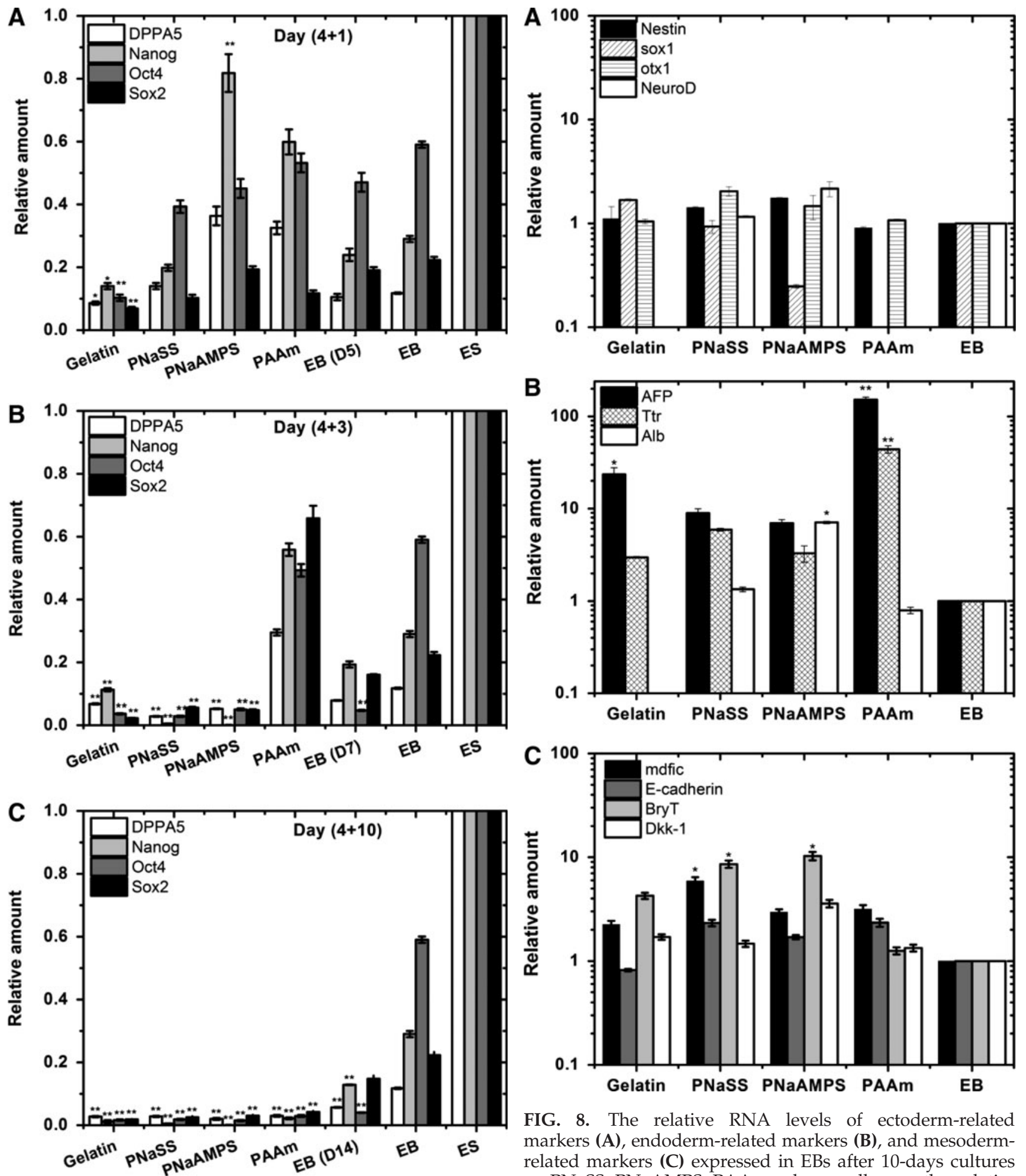

FIG. 8. The relative RNA levels of ectoderm-related markers (A), endoderm-related markers (B), and mesodermrelated markers $(\mathbf{C})$ expressed in EBs after 10-days cultures on PNaSS, PNaAMPS, PAAm gels as well as on the gelatincoated PS culture plate. Data are shown for (A) nestin, sox1, otx1, Neuro D, (B) AFP, Ttr, Alb, and (C) mdfic, E-cadherin, Bry $T$, and $D k k-1$. The error ranges represent the standard deviation over 3-6 samples. All the results were normalized to those of EBs before seeding. ${ }^{*} p<0.5$ versus the gene expressions of EBs before loading. ${ }^{* *} p<0.01$ versus the gene expressions of EBs before loading.

FIG. 7. Real-time polymerase chain reaction analysi DPPA5, Nanog, Otc4, and Sox2 gene expressions of EBs after 1 day (A), 3 days (B), and 10 days (C) culture on different substrates. The relative amount of each gene expression in the figure is against pluripotent mouse ES cells. The initially formed EB and EBs cultured in suspension were analyzed too. ${ }^{*} p<0.5$ versus the gene expressions of EBs before loading. ${ }^{* *} p<0.01$ versus the gene expressions of EBs before loading. 

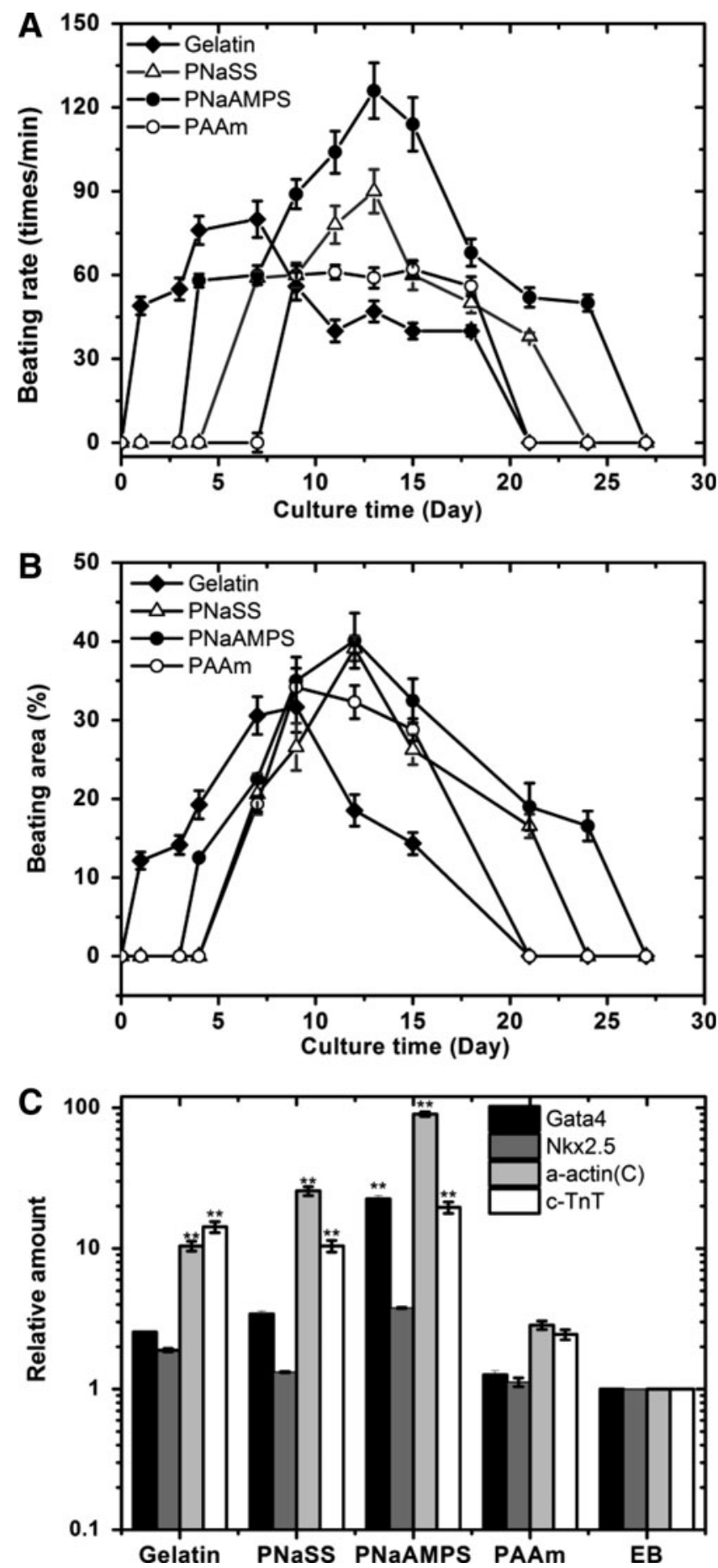

FIG. 9. The existence of mouse ES cell derived cardiomyocytes on various substrates. The time profiles of beating rates (A) and beating area (B) of EBs on various substrates were evaluated by the optical microscope. (C) The relative RNA levels of cardiomyocyte-related markers expressed in EBs cultured on various substrates for 10 days. Data are shown for Gata-4, Nkx2.5, $\alpha$-actin(c), and c-Tnt. The error ranges represent the standard deviation over three samples. All the results were normalized to those of EBs before seeding. ${ }^{*} p<0.5$ versus the gene expressions of EBs before loading. ${ }^{* *} p<0.01$ versus the gene expressions of EBs before loading. level to lower level as follows: PNaAMPS gels, PNaSS gels, gelatin-coated PS, and neutral PAAm gels. These results were also confirmed by the immunostaining results (Fig. 10), which indicated that cardiomyoctes differentiation was affected by the surface charge of hydrogel substrates.

\section{Discussion}

\section{Effects of the surface properties of hydrogels on the differentiation of EBs}

EBs morphologies, EBs adhesions to the substrates, cells spreading and differentiations are time dependent. These dynamic behaviors of EBs are determined by the balance between the cell-cell interaction and cell-substrate interaction. The protein-mediated interaction between substrates and cells could be influenced not only by van der Waals interaction that is strongly dependent on the hydrophilic/hydrophobic property of scaffolds, but also by electrostatic interaction between charged moieties that is dependent on the surface charges of the scaffolds. ${ }^{34}$ FAs are also involved in this process.

At early differentiation phase (day $4+1$ ), the low protein adsorption on PAAm and PNaAMPS gels (Fig. 2) was not in favor of cell-substrate adhesion, as a result, cell-cell adhesion within EBs was dominant and 3D spherical morphologies were observed (Fig. 3). At the same time, the undifferentiation-related expressions were in high level in this case (Figs. 6 and 7). However, high protein adsorption on PNaSS hydrogels (Fig. 2) was in favor of cell-substrate adhesion, hence cells within EBs were adhered quickly (Fig. 3 ) and the undifferentiation-related markers decreased at the same time (Figs. 6 and 7).

At an intermediate phase (day $4+3$ ), the EBs behaviors on negatively charged gels were distinctly different from that on neutral PAAm gels. The adhesive interaction between the cell and the gel is weak in the case of the neutral polymer gel via the van der Waals interaction, while the interaction is greatly enhanced by the negative charges of the gel via the electrostatic interaction. As a result, on neutral PAAm gels, inhibition of spreading of ES cells on this substrate is in favor of cell aggregation, resulting in enhancement of growth factors originated from pluripotent ES cells within EBs. While on negatively charged gels, because the similar charge properties with close Zeta potential (near $-20 \mathrm{mv}$ ), ${ }^{30,31}$ the cell-substrate adhesion is upregulated by the negative charge and the undifferentiation-related expressions are at a lower level than on neutral PAAm gels.

At terminal differentiation phase (day $4+10$ ), the upregulation of mesoderm and endoderm-related expressions were found on all of hydrogels with diverse levels of spontaneous cardiomyocytes differentiation. Nonspreading EBs on neutral PAAm gels upregulate the cell-cell interactions in the EBs structures and stimulate the expressions of mesendoderm and early cardiac cell-lineage, which can provide cardiomyogenic-inducing factors. However, the capacity of diffusive transport was inhibited by the three dimensional structure that affected cardiomyocytes differentiation to some extent. Consequently, the spontaneous cardiomyocyte differentiation on neutral PAAm gels was not higher than that on negatively charged gels (Fig. 9).

As to EBs cultured on negatively charged hydrogels, the establishments of FAs were well observed at a higher level on PNaAMPS and PNaSS hydrogels than that on neutral 

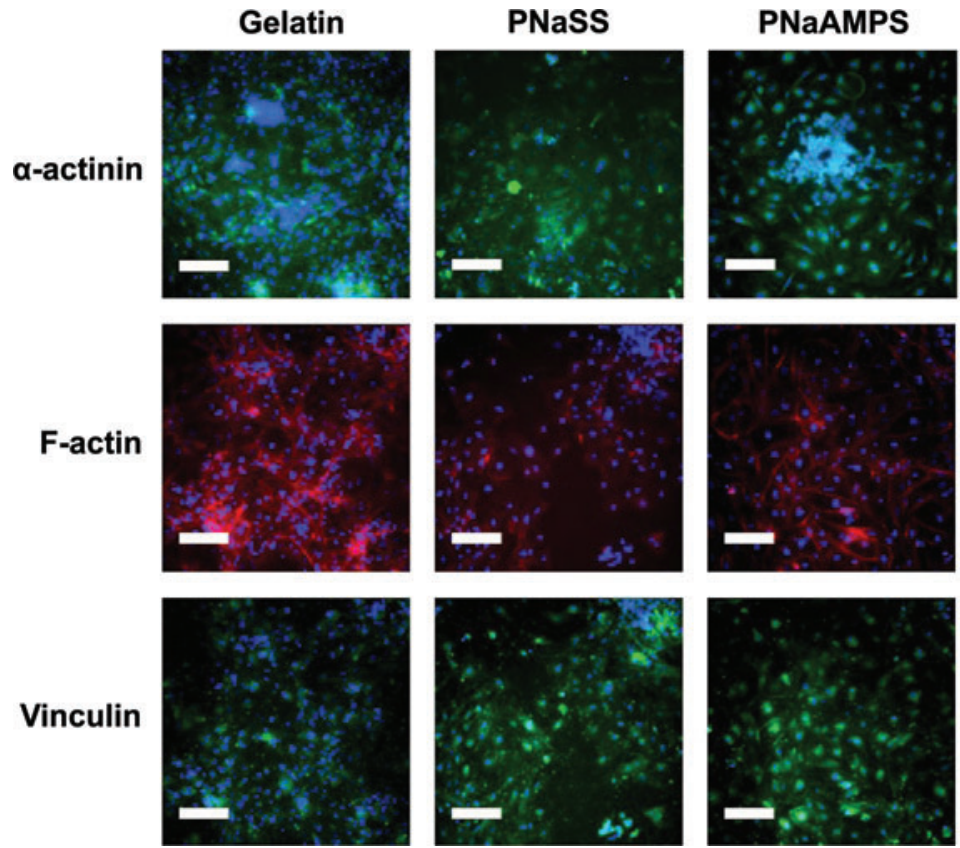

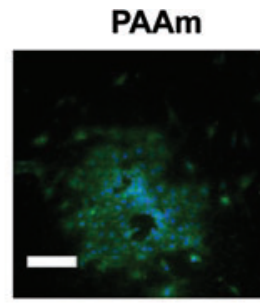

FIG. 10. Immunofluorescence staining images of $\alpha$-actinin (green), F-actin (red), and vinculin (green) in cells within EBs cultured for 10 days on PNaSS, PNaAMPS, and PAAm gels as well as on the gelatin-coated PS culture plate. Nuclei were stained with blue color. Scale bar: $100 \mu \mathrm{m}$. Color images available online at www .liebertonline.com/tea

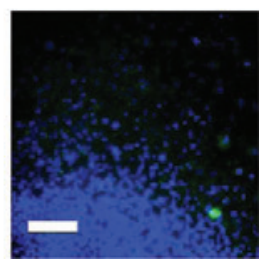

PAAm gels (Fig. 10). Cells within EBs adhered onto the negatively charged hydrogel surface and were differentiated. Meanwhile, the PNaAMPS and PNaSS hydrogels have similarities with proteoglycans in its negative charge and sulfonic acid group, which may directly function as a signal molecular to interact with receptors for signal pathways in cardiomyocyte differentiation. Hence, EBs can differentiate on these negatively charged hydrogels with high efficiency of cardiomyocytes differentiation. Besides, PNaAMPS gel with lower ECM protein adsorption was more favorable to EBs spontaneous cardiomyocytes differentiation than that on PNaSS gels. The difference may result from the chemical structure by influencing signal pathways in development of EBs. The mechanism is not unclear now and needs to be studied in the future.

\section{Conclusions}

In this study, the dynamic behaviors of EBs cultured on different substrates in the absence of surface modification and inducible bioactive factors were investigated. Negatively charged PNaAMPS and PNaSS gels were first used for EBs $2 \mathrm{D}$ culture. The results showed that EBs differentiations were affected by the balance between the cell-cell interaction and cell-substrate adhesion at different time points.

High protein adsorption on negatively charged PNaSS hydrogels favored cell-substrate adhesion, hence cells within EBs were adhered quickly and the undifferentiation-related markers decreased at early differentiation phase (day $4+1$ ). This hydrogel can promote EB adhesion to the substrate and then facilitate cell spreading and migration in the later period, just like that on gelatin-coated PS culture plate. The van der Waals attraction, electrostatic repulsion and FAs were all involved in this process. Hence, EBs can differentiate on this negatively charged gel along with upregulation of mesoderm- and endoderm-related expressions and high efficiency of spontaneous cardiomyocyte differentiation.
Low protein adsorption on negatively charged PNaAMPS hydrogels was not in favor of cells-substrate adhesion at early differentiation phase (day $4+1$ ), and similar morphology and gene profiles with neutral PAAm gels were found in this case. However, after 3-days cultures, because of the similar charge properties with PNaSS gels, the cell-substrate adhesion was upregulated by the negative charge and EBs adhesion and differentiation were similar to that of PNaSS gels. It is necessary to note that PNaAMPS gel with lower ECM protein adsorption is more favorable to EBs spontaneous cardiomyocytes differentiation than that on PNaSS gels.

While low protein adsorption on neutral PAAm hydrogels was not in favor of cells-substrate adhesion, cell-cell adhesion within EBs was dominant. EBs maintained the initial cells aggregated morphology with high expression of pluripotency-related markers in the short culture periods, and then possessed significantly greater levels of selected endoderm markers after long-time culture. Cell-cell interactions in the EBs structures stimulate the expression of markers for mesendoderm and cardiac cell-lineage at the same time.

\section{Acknowledgments}

This study was supported by a Grant-in-Aid for Specially Promoted Research (No. 18002002) from the Ministry of Education, Science, Sports and Culture of Japan.

\section{Disclosure Statement}

No competing financial interests exist.

\section{References}

1. Hwang, N.S., Varghese, S., and Elisseeff, J. Controlled differentiation of stem cells. Adv Drug Deliv Rev 60, 199, 2008.

2. Hopfl, G., Gassmann, M., and Desbaillets, I. Differentiating embryonic stem cells into embryoid bodies. Methods Mol Biol 254, 79, 2004. 
3. Fridley, K.M., Fernandez, I., Li, M.T.A., Kettlewell, R.B., and Roy, K. Unique differentiation profile of mouse embryonic stem cells in rotary and stirred tank bioreactors. Tissue Eng Part A 16, 3285, 2010.

4. Desbaillets, I., Ziegler, U., Groscurth, P., and Gassmann M. Embryoid bodies: an in vitro model of mouse embryogenesis. Exp Physiol 85, 645, 2000.

5. Kehat, I., Kenyagin-Karsenti, D., Snir, M., Segev, H., Amit, M., Gepstein, A., Livne, E., Binah, O., Itskovitz-Eldor, J., and Gepstein, L. Human embryonic stem cells can differentiate into myocytes with structural and functional properties of cardiomyocytes. J Clin Invest 108, 407, 2001.

6. Dani, C., Smith, A.G., Dessolin, S., Leroy, P., Staccini, L., Villageois, P., Darimont, C., and Ailhaud, G. Differentiation of embryonic stem cells into adipocytes in vitro. J Cell Sci 110, 1279, 1997.

7. Kramer, J., Hegert, C., Guan, K.M., Wobus, A.M., Muller, P.K., and Rohwedel, J. Embryonic stem cell-derived chondrogenic differentiation in vitro: activation by BMP-2 and BMP-4. Mech Dev 92, 193, 2000.

8. Schuldiner, M., Yanuka, O., Itskovitz-Eldor, J., Melton, D.A., and Benvenisty, N. Effects of eight growth factors on the differentiation of cells derived from human embryonic stem cells. Proc Natl Acad Sci USA 97, 11307, 2000.

9. Goldring, M.B., Tsuchimochi, K., and Ijiri, K. The control of chondrogenesis. J Cell Biochem 97, 33, 2006.

10. Burdick, J.A., and Vunjak-Novakovic, G. Engineered microenvironments for controlled stem cell differentiation. Tissue Eng Part A 15, 205, 2009.

11. Vacanti, J.P., and Langer, R. Tissue engineering: the design and fabrication of living replacement devices for surgical reconstruction and transplantation. Lancet 354, S32, 1999.

12. Dawson, E., Mapili, G., Erickson, K., Taqvi, S., and Roy, K. Biomaterials for stem cell differentiation. Adv Drug Deliv Rev 60, 215, 2008.

13. Nguyen, K.T., and West, J.L. Photopolymerizable hydrogels for tissue engineering applications. Biomaterials 23, 4307, 2002.

14. Georges, P.C., and Janmey, P.A. Cell type-specific response to growth on soft materials. J Appl Physiol 98, 1547, 2005.

15. Lee, H.J., Lee, J.S., Chansakul, T., Yu, C., Elisseeff, J.H., and $\mathrm{Yu}$, S.M. Collagen mimetic peptide-conjugated photopolymerizable PEG hydrogel. Biomaterials 27, 5268, 2006.

16. Drury, J.L., and Mooney, D.J. Hydrogels for tissue engineering: scaffold design variables and applications. Biomaterials 24, 4337, 2003.

17. Liu, S.Q., Tay, R., Khan, M., Rachel Ee, P.L., Hedrick, J.L., and Yang, Y.Y. Synthetic hydrogels for controlled stem cell differentiation. Soft Matter 6, 67, 2010.

18. Hwang, N.S, Varghese, S., Zhang, Z., and Elisseeff, J. Chondrogenic differentiation of human embryonic stem cellderived cells in arginine-glycine-aspartate modified hydrogels. Tissue Eng 12, 2695, 2006.

19. Weber, L.M., Hayda, K.N., Haskins, K., and Anseth, K.S. The effects of cell-matrix interactions on encapsulated betacell function within hydrogels functionalized with matrixderived adhesive peptides. Biomaterials 28, 3004, 2007.

20. Nicodemus, G.D., and Bryant, S.J. The role of hydrogel structure and dynamic loading on chondrocyte. J Biomech 41, 528, 2008.

21. Engler, A.J., Sen, S., Sweeney, H.L., and Discher, D.E. Matrix elasticity directs stem cell lineage specification. Cell 126, 677, 2006.

22. Fedorovich, N.E., Alblas, J., de Wijn, J.R., Hennink, W.E., Verbout, A.J., and Dhert, W.J. Hydrogels as extracellular matrices for skeletal tissue engineering: state-of-the-art and novel application in organ printing. Tissue Eng 13, 1905, 2007.

23. Young, T.H., Tu, H.R., Chan, C.C., Huang, Y.C., Yen, M.H., Cheng, N.C., Chiu, H.C., and Lin, S.J. The enhancement of dermal papilla cell aggregation by extracellular matrix proteins through effects on cell-substratum adhesivity and cell motility. Biomaterials 30, 5031, 2009.

24. Ryan, P.L., Foty, R.A., Kohn, J., and Steinberg, M.S. Tissue spreading on implantable substrates is a competitive outcome of cell-cell vs. cell-substratum adhesivity. Proc Natl Acad Sci USA 98, 4323, 2001.

25. Young, T.H., Lee, C.Y., Chiu, H.C., Hsu, C.J., and Lin, S.J. Self-assembly of dermal papilla cells into inductive spheroidal microtissues on poly (ethylene-co-vinyl alcohol) membranes for hair follicle regeneration. Biomaterials 29, 3521, 2008.

26. Lin, S.J., Jee, S.H., Hsaio, W.C., Lee, S.J., and Young, T.H. Formation of melanocyte spheroids on the chitosan-coated surface. Biomaterials 26, 1413, 2005.

27. Kundu, A.K., Khatiwala, C.B., and Putnam, A.J. Extracellular matrix remodeling, integrin expression, and downstream signaling pathways influence the osteogenic differentiation of mesenchymal stem cells on poly(lactide-coglycolide) substrates. Tissue Eng Part A 15, 273, 2009.

28. Moreau, J.E., Bramono, D.S., Horan, R.L., Kaplan, D.L., and Altman, G.H. Sequential biochemical and mechanical stimulation in the development of tissue-engineered ligaments. Tissue Eng Part A 14, 1161, 2008.

29. Ryan, P.L., Foty, R.A., Kohn, J., and Steinberg, M.S. Tissue spreading on implantable substrates is a competitive outcome of cell-cell vs. cell-substratum adhesivity. Proc Natl Acad Sci USA 98, 4323, 2001.

30. Chen, Y.M., Shiraishi, N., Satokawa, H., Kakugo, A., Narita, T., Gong, J.P., Osada, Y., Yamamoto, K., and Ando, J. Cultivation of endothelial cells on adhesive protein-free synthetic polymer gels. Biomaterials 26, 4588, 2005.

31. Chen, Y.M., Ogawa, R., Kakugo, A., Osada, Y., and Gong, J.P. Dynamic cell behavior on synthetic hydrogels with different charge densities. Soft Matter 5, 1804, 2009.

32. Chen, Y.M., Gong, J.P., Tanaka, M., Yasuda, K., Yamamoto, S., Shimomura, M., and Osada, Y. Tuning of cell proliferation on tough gels by critical charge effect. J Biomed Mater Res A 88, 74, 2009.

33. Chen, Y.M., Yang, J.J., and Gong, J.P. Adhesion, spreading, and proliferation of endothelial cells on charged hydrogels. J Adhes 85, 839, 2009.

34. Yang, J.J., Chen, Y.M., Liu, J.F., Kurokawa, T., and Gong, J.P. Spontaneous redifferentiation of dedifferentiated human articular chondrocytes on hydrogel surfaces. Tissue Eng Part A 16, 2529, 2010.

35. Kwon, H.J., Yasuda, K., Ohmiya, Y., Honma, K., Chen, Y.M., and Gong, J.P. In vitro differentiation of chondrogenic ATDC5 cells is enhanced by culturing on synthetic hydrogels with various charge densities. Acta Biomater 6, 494, 2010.

36. Gong, J.P., Katsuyama, Y., Kurokawa, T., and Osada, Y. Double-network hydrogels with extremely high mechanical strength. Adv Mater 15, 1155, 2003.

37. Chastain, S.R., Kundu, A.K., Dhar, S., Calvert, J.W., and Putnam, A.J. Adhesion of mesenchymal stem cells to polymer scaffolds occurs via distinct ECM ligands and controls their osteogenic differentiation. J Biomed Mater Res A 78, 73, 2006. 
38. Yamashita, J., Itoh, H., Hirashima, M., Ogawa, M., Nishikawa, S., Yurugi, T., Naito, M., Nakao, K., and Nishikawa, S.I. Flk1-positive cells derived from embryonic stem cells serve as vascular progenitors. Nature 408, 92, 2000.

39. Yamamoto, K., Sokabe, T., Watabe, T., Miyazono, K., Yamashita, J.K., Obi, S., Ohura, N., Matsushita, A., Kamiya, A., and Ando, J. Fluid shear stress induces differentiation of Flk1-positive embryonic stem cells into vascular endothelial cells in vitro. Am J Physiol Heart Circ Physiol 288, H1915, 2005.

40. Gassmann, M., Donoho, G., and Berg, P. Maintenance of an extrachromosomal plasmid vector in mouse embryonic stem cells. Proc Natl Acad Sci 92, 1292, 1995.

41. Kurosawa, H. Methods for inducing embryoid body formation: in vitro differentiation system of embryonic stem cells, J Biosci Bioeng 103, 389, 2007.

42. Dang, S.M., Kyba, M., Perlingeiro, R., Daley, G.Q., and Zandstra, P.W. Efficiency of embryoid body formation and hematopoietic development from embryonic stem cells in different culture systems. Biotechnol Bioeng 78, 442, 2002.

43. Ma, W., Fitzgerald, W., Liu, Q.Y., O'Shaughnessy, T.J., Maric, D., Lin, H.J., Alkon, D.L., and Barker, J.L. CNS stem and progenitor cell differentiation into functional neuronal circuits in three-dimensional collagen gels. Exp Neurol 190, 276, 2004.

44. Baharvand, H., Azarnia, M., Parivar, K., and Ashtiani, S.K. The effect of extracellular matrix on embryonic stem cellderived cardiomyocytes. J Mol Cell Cardiol 38, 495, 2005.

45. Muller, M., Fleischmann, B.K., Selbert, S., Ji, G.J., Endl, E., Middeler, G., Muller, O.J., Schlenke, P., Frese, S., Wobus, A.M., Hescheler, J., Katus, H.A., and Franz, W.M. Selection of ventricular-like cardiomyocytes from ES cells in vitro. FASEB J 14, 2540, 2000.

46. O'Connor, M.D., Kardel, M.D., Iosfina, I., Youssef, D., Lu, M., Li, M.M., Vercauteren, S., Nagy, A., and Eaves, C.J. Alkaline phosphatase-positive colony formation is a sensitive, specific, and quantitative indicator of undifferentiated human embryonic stem cells. Stem cells 26, 1109, 2008.

47. Palmqvist, L., Glover, C.H., Hsu, L., Lu, M., Bossen, B., Piret, J.M., Humphries, R.K., and Helgason, C.D. Correlation of murine embryonic stem cell gene expression profiles with functional measures of pluripotency. Stem Cells 23, 663, 2005.

48. Latour, R.A. Biomaterials: protein-surface interactions. In: Wnek, G.E., and Bowlin, G.L., eds. The Encyclopedia of Biomaterials and Biomedical Engineering. London: Informa Healthcare, 2005, pp. 1-15.

49. Sivaraman, B., Fears, K.P., and Latour, R.A. Investigation of the effects of surface chemistry and solution concentration on the conformation of adsorbed proteins using an improved circular dichroism method. Langmuir 25, 3050, 2009.

50. Calonder, C., Matthew, H.W.T., and Van Tassel, P.R. Adsorbed layers of oriented fibronectin: A strategy to control cell-surface interactions. J Biomed Mater Res A 75A, 316, 2005.

51. Cohavi, O., Corni, S., De Rienzo, F., Di Felice, R., Gottschalk, K.E., Hoefling, M., Kokh, D., Molinari, E., Schreiber, G., Vaskevich, A., and Wade, R.C. Protein-surface interactions: challenging experiments and computations. J Mol Recognit 23, 259, 2010.

52. Wertz, C.F., and Santore, M.M. Effect of surface hydrophobicity on adsorption and relaxation kinetics of albumin and fibrinogen: single-species and competitive behavior. Langmuir 17, 3006, 2001.

53. Steele, J.G., Dalton, B.A., Johnson, G., and Underwood, P.A. Adsorption of fibronectin and vitronectin onto Primaria and tissue culture polystyrene and relationship to the mechanism of initial attachment of human vein endothelial cells and BHK-21 fibroblasts. Biomaterials 16, 1057, 1995.

54. Wilson, C.J., Clegg, R.E., Leavesley, D.I., and Pearcy, M.J. Mediation of biomaterial-cell interactions by adsorbed proteins: a review. Tissue Eng 11, 1, 2005.

55. Maltsev, V.A., Wobus, A.M., Rohwedel, J., Bader, M., and Hescheler, J. Cardiomyocytes differentiated in vitro from embryonic stem cells developmentally express cardiacspecific genes and ionic currents. Circ Res 75, 233, 1994.

56. Kubo, A., Shinozaki, K., Shannon, J.M., Kouskoff, V., Kennedy, M., Woo, S., Fehling, H.J., and Keller, G. Development of definitive endoderm from embryonic stem cells in culture. Development 131, 1651, 2004.

57. Sachinidis, A., Fleischmann, B.K., Kolossov, E., Wartenberg, M., Sauer, H., and Hescheler, J. Cardiac specific differentiation of mouse embryonic stem cells. Cardiovasc Res 58, 278, 2003.

Address correspondence to: Jian Ping Gong, Dr. Sci. Faculty of Advanced Life Science Hokkaido University Nita 10, Nishi 8, Kita-ku Sapporo 060-0810 Japan

E-mail: gong@mail.sci.hokudai.ac.jp

Received: January 18, 2011 Accepted: May 5, 2011

Online Publication Date: June 15, 2011 
